This is an article forthcoming/accepted in the Journal of Medical Ethics,

Please cite the published version from the JME website.

https://jme.bmj.com/

http://dx.doi.org/10.1136/medethics-2018-105294

Mr. Joona Räsänen, University of Oslo, Norway; Aalto University, Finland.

\title{
A MORAL CASE FOR LEGAL AGE CHANGE
}

\begin{abstract}
:
Should a person who feels his legal age does not correspond with his experienced age be allowed to change his legal age? In this paper, I argue that in some cases people should be allowed to change their legal age. Such cases would be when: 1) the person genuinely feels his age differs significantly from his chronological age and 2) the person's biological age is recognized to be significantly different from his chronological age and 3) age change would likely prevent, stop or reduce ageism, discrimination due to age, he would otherwise face. I also consider some objections against the view that people should be allowed to change their legal age and find them lacking.
\end{abstract}

\section{Introduction}

Suppose that someone feels his age is not correct and wants to make himself legally 20 years younger on the grounds that he is being discriminated against due to his old age. Should he be allowed to change his legal age?

The question is not a joke, at least if we believe that Dutchman Emile Ratelband is being serious. ${ }^{1}$ Ratelband (legal age of 69) claims that he is often discriminated against because of his old age. He states that due to having an official age that does not reflect his emotional state he is struggling to find both work and love. Therefore, he has asked a Dutch court to change his date of birth to 20 years later to his current birthday. ${ }^{\text {ii }}$

Here, I consider whether there are compelling moral arguments for the view that people should be allowed to change their legal age. The structure of the paper is the following: After clarifying some groundwork, I make the argument why, and in what cases, people should be

\footnotetext{
${ }^{\mathrm{i}}$ Legal age (or official age) should be understood here as the age one is according to legal documents such as passport. To change one's legal age, therefore, would mean to change one's birth date in these documents. Legal age is important because many rights and duties depend on one's legal age (the right to vote, drive a car or drink alcohol, for example). ${ }^{i i}$ During the revision of this paper, the Dutch court has rejected the appeal to change Ratelband's age.
} 
allowed to change their legal age. I then consider some immediate objections against the view that people should be allowed to change their age and show why they are unsuccessful.

Before going into the arguments, some clarifications are needed. First, I do not deny the fact that there is a certain chronological age - the length of time that each particular person has existed. With most people, chronological age corresponds well with emotional and biological age and thus it is often unproblematic that legal age equals chronological age. ${ }^{\text {iii }}$ But this is not always the case. I argue that sometimes, it is ethically permissible for people to change their legal age so that it matches their biological and emotional age - even though this would be contrary to their chronological age. ${ }^{\text {iv }}$

Second, some people might claim that because sex change is permissible, age change should also be permissible. While I feel certain sympathy for this strategy, I do not argue from analogy: that because sex change is permissible, so is age change. The aim of this paper is to make an independent argument that will work whether or not one accepts the claim that sex change is both possible and permissible.

I am interested in cases where a person faces discrimination because of his age and has a mismatch between his emotional and chronological age and a mismatch between his biological and chronological age. The reason for this is two-fold. First, if there are no compelling arguments for legal age change when both mismatches and the risk of being discriminated against are present, then, there is unlikely to be a case for legal age change when just one of the mismatches or discrimination is present. Second, if there is a compelling argument for legal age change in cases where the three conditions are met, this opens up further research questions such as what are the sufficient and necessary conditions for age change. However, it is beyond this study to determine these conditions. My aim here is simply to argue that at least on some occasions it is possible to give a moral justification for legal age change.

\section{A moral argument for age change: preventing discrimination}

In this section, I make a moral argument for the view that in some cases, people should be allowed to change their legal age. What kinds of motives might someone who wants to change his legal age have?

A possible reason for wanting to change one's legal age is discrimination based on age. ${ }^{\mathrm{v}}$ The argument for age change that is built on age discrimination, ageism, can be framed as follows.

P1) Legal age is a cause of severe discrimination for some people whose biological and emotional age do not match their chronological age.

\footnotetext{
${ }^{\text {iii }}$ For example, we think 18-year-olds are more capable of acting responsibly than 16-yearolds, and we think the eyesight of 80 -year-olds is weaker than 60 -year-olds - because often that is the case. So while it is often appropriate to believe that legal age equals chronological age, this reasoning does not always apply.

${ }^{\text {iv }}$ By emotional age (or experienced age) I refer to the age someone feels and identifies himself. By biological age (or physiological age) I refer to the age one's body and mind appear to others by objective measures.

${ }^{\mathrm{v}}$ For an overview of philosophy and ageism see Lesser H, Ageism, in R. Chadwick (ed.), Encyclopedia of Applied Ethics, vol. 1. San Diego, Academic Press, 1998, pp. 87-94.
} 
P2) People should be allowed to secure relief from severe discrimination against them unless this has excessive consequences.

P3) Changing a person's legal age would not, in the case of people whose biological and emotional age do not match their chronological age, have excessive consequences.

C) People whose biological and emotional age do not match their chronological age should be allowed to change their legal age in order to secure relief from discrimination.

There are reasons to endorse the first premise. Ageism, discrimination on the grounds of age, is a real and common phenomenon. Perhaps the most obvious place where ageism is present is the workplace or the instances of hiring. Ageism in hiring has been shown to exist in many countries such as Belgium ${ }^{2}$, England ${ }^{3}$, Spain ${ }^{4}$, and Sweden ${ }^{5}$.

While discrimination based on age exists, one might believe that it is not morally wrong to discriminate against based on age. One might thus contest the argument by claiming that ageism is not wrong at all. Here, I assume that wrongness of discrimination is built on the following features.

i) Discrimination is based on membership in a socially salient group that the individual being discriminated against does not consciously choose to belong to.

ii) Discriminatory conduct imposes some kind of disadvantage or harm on the persons at whom it is directed.

The groups must be 'socially salient', meaning that the groups must be important to the structure of social interactions across a wide range of social contexts. ${ }^{6}$ So, groups based on race, religion, age or gender qualify as grounds for discrimination, but groups based on musical or culinary tastes, or other personal preferences of persons do not. Belonging to the former groups is also something that is not consciously chosen, unlike choosing to belong to a neo-Nazi party, for example. Since being a specific age can be understood as belonging to a specific socially salient group that one does not choose to belong to (such as teenagers, early mid-life, late mid-life, young old, elderly etc.) and because discrimination against someone because he belongs to such a group imposes economic and psychological disadvantages for him - and thus harms him - discrimination based on age is morally wrong. ${ }^{\text {vi }}$

However, not all who want to change their legal age suffer from ageism. And not all who suffer from ageism have mismatches between their emotional, biological and chronological ages. My argument does not cover these instances. The aim here is simply to show that at least in some cases there are compelling moral arguments for age change and, therefore, legal age change should be permitted in such cases. Because some people who have mismatches between their ages face ageism, there is a reason to endorse the first premise.

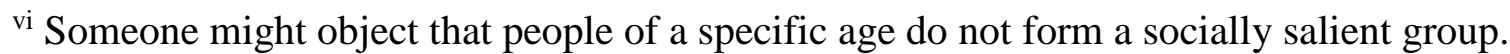
Those who are willing to accept that there is nothing wrong in discriminating based on age (because age does not form a socially salient group) might not be convinced by this paper. Those who believe ageism is wrong but who reject the view that in order to face wrongful discrimination the one being discriminated against must belong to a socially salient group could just replace their own definition of discrimination that would include ageism.
} 
There are also reasons to endorse the second premise: people should be allowed to secure relief from severe discrimination unless this has excessive consequences. The premise is based on an assumption that changing age would in fact secure relief from discrimination. It seems correct that if a person suffering from ageism were able to change his legal age to younger, he would face less discrimination in hiring. An analogy might help illustrate this. Certain minorities, such as Muslim immigrants, are often discriminated against in hiring because of their foreign names. Studies in Sweden have shown that when immigrants have changed their names, they have faced less discrimination in hiring ${ }^{7}$ and their annual earnings have increased substantially ${ }^{8}$. That is because discrimination was reduced after the name change.

Similarly, if those who are discriminated against because of their age had the option to change their legal age, they would face less discrimination in hiring and at the workplace. That is because others would not be aware of their chronological age and they would therefore receive more invitations for job interviews. ${ }^{\mathrm{vii}} \mathrm{I}$ believe it is clear that people should be allowed to secure relief from severe discrimination unless this has excessive consequences.

The third premise stated that changing a person's legal age would not, in the case of people whose biological and emotional age do not match their chronological age, have excessive consequences. What kind of consequences could be excessive enough to prohibit age change? In some cases, such consequences could be costs for an age change candidate, such as not being allowed to collect retirement benefits but having to go back to work. The choice of whether this or other similar costs are severe enough so that age change would not be a better option should be left to the age change candidate. In the next section, I consider some other consequences that could undermine the argument.

So far, I have presented an argument for legal age change. According to the argument, age change would be a way to prevent, stop or reduce ageism, discrimination based on (old) age. Next, I consider some immediate objections against the view that people should be allowed to change their legal age. I show that the objections are lacking argumentative power.

\section{Potential objections and replies}

In this section, I respond to possible objections against the view that people should be allowed to change their legal age. Some of the replies are mere clarifications of my position and others are more fulsome responses to deeper objections.

Objection 1. Age is a biological fact that cannot be changed. Biological age equals chronological age. Age change should not, therefore, be allowed because it is impossible.

Reply. This objection is misplaced. I do not deny the existence of chronological age, the period of time a person has been alive and existed. It would be impossible to change this age. But, besides this chronological age, there are other ages such as emotional and biological age.

\footnotetext{
${ }^{\text {vii }}$ Of course, the job candidates who have changed their age might be rejected at the interview stage, but it would be unlikely that this were due discrimination because employers would not be able to know the candidate's chronological age (hiding one's chronological age seems to be behind the reasoning of age change in the first place).
} 
There is nothing logically implausible in changing legal age, while it might be implausible to change biological or chronological age. ${ }^{\text {viii }}$

This objection is not compelling for another reason. The claim that a person's biological age always corresponds with his chronological age is false. People age at different rates. People's body parts also age at different rates, and how fast our cells deteriorate depends on various factors, including genetics, epigenetics and lifestyle. To illustrate this, consider two fictional but plausible cases.

Alan (chronological age of 50) drinks and smokes heavily, does not exercise, eats unhealthily and has a stressful job. Alan visits a doctor for a medical check-up. The doctor examines Alan and tells him that his body is that of a 60 -year-old man.

Bob (chronological age of 50) does not smoke or drink, exercises, eats healthily and has a less stressful job. Bob visits a doctor for a medical check-up. The doctor examines Bob and tells him that his body is that of a 40 -year old man.

While the chronological ages of Alan and Bob are both 50 years, Alan's biological age is 60 while Bob's biological age is 40 . Thus, biological age does not always correspond with chronological age. This has been confirmed by medical research. For example, major depression has been associated with higher epigenetic ageing in blood as measured by DNA methylation (DNAm) patterns. As the researchers of this recent study stated: 'As compared with control subjects, patients with major depression exhibited higher epigenetic aging in blood and brain tissue, suggesting that they are biologically older than their corresponding chronological age.' 9

Objection 2. An old person should not be allowed to change his age to younger because he might endanger himself and others at the workplace. Age change would thus have excessive consequences and because of that, the third premise is mistaken.

Reply. This objection fails. It is true that in general, age limits exist for good reason, such as prohibiting a 90-year-old from become an airline pilot because he would pose a safety risk. Nevertheless, if by medical and psychological examination it is possible to determine that a person's biological and psychological age are significantly lower than his chronological age then such a person would not be a safety risk at a workplace. Even if this objection were successful, it would merely show that in some cases age change should be prohibited, not that it should be prohibited in all cases, because not all old people pose safety risks and not all jobs are of the sort where people's lives might be in danger. On the other hand, if one claims that an old person poses a safety risk because of his old age and despite his physical and psychological abilities, the objector merely expresses his own ageism.

Objection 3. Age change is expensive for society, at least if it becomes reasonably common and every age change candidate needs to be individually tested and evaluated by medical

\footnotetext{
${ }^{\text {viii }}$ Many people, of course, make significant efforts to keep themselves biologically young and try to stop or slow down ageing. Philosophers and bioethicists, likewise, put forth and evaluate arguments for the views that we should prevent ageing or even death. See for example. Bostrom N. The fable of the dragon tyrant. J. Med. Ethics 2005;31:273-277; Minerva F. The Ethics of Cryonics. Palgrave Macmillan, 2018.
} 
doctors and psychologists. The third premise is therefore false and due to these excessive reasons, age change should not be allowed. ${ }^{\text {ix }}$

Reply. The objection somewhat misses the goal because it is an objection against the view that age change should be publicly funded, and it is not obvious that it should. Healthcare rationing is inevitable because of limited resources. If the process of age change were very expensive, the state could demand that the applicant cover the costs of age change himself. It is worth noting that to society, changing age would at least in some cases be beneficial (such as when a person would stop collecting government retirement benefits and go back to work instead). Therefore, in some cases, the state would also have an interest to endorse age change policy according to cost-benefit analysis.

Objection 4. Someone changing his legal age older could have psychological problems because the person cannot know how it would feel like to be acknowledged as older because he has not been that old before. Thus, changing one's age could be psychologically dangerous and therefore it should be prohibited.

Reply. If successful, this objection shows that age change should be prohibited when a person wants to change his legal age to older, not when a person wants to change his age to younger. Persons who want to change their legal age to younger, such as Emile Ratelband, have been younger before, therefore they know what it feels like. Changing legal age to younger is not a jump into the unknown - it is to match a person's legal age with his emotional and biological age and to acknowledge the lived experience of the person.

Nevertheless, while I admit that changing age might in some cases be a 'transformative experience ${ }^{10}$, so that age change would have an effect on the sort of person we will be, this is not a reason to oppose age change. After all, there are many choices and decisions that are transformative in this way (such as whether one will have children ${ }^{11}$ ), but it seems they should still not be prohibited because in human life it is inevitable to face choices that transform us.

Objection 5. If people should be allowed to change their legal age then people should be allowed to change, for example, their legal height as well. But this cannot be right; therefore people should not have a right to change their legal age either. In fact, the existence of this article supports the claim that legalizing sex change has led to demanding the legalization of age change, and similarly age change might lead to height change.

Reply. This slippery slope argument comes in two forms: causal and logical. ${ }^{12}$ According to the causal version of the argument, legalizing age change would be a path to legalizing height change as well. Because we should not allow people to change their legal height, we should not allow people to change their age either.

The problem of the causal version of the objection is that there is no evidence to suggest that legalizing age change would be the cause (or part of it) in legalizing height change. In fact, the evidence shows the opposite. For example, legalizing sex change has not led to legalizing race change or age change - despite the existence of this article (or the article defending race change $^{13}$ ). The problem thus is that the legalization of sex change or age change does not cause the other. A third factor causes them both. This third factor could be, for example, the

\footnotetext{
${ }^{i x}$ I thank anonymous referees for pressing me on this one.
} 
belief that people should be free to choose their identity when they do not harm others and when they would otherwise face discrimination.

The other form of the slippery slope argument is the logical one. According to this objection, the principles behind age change and height change are the same and therefore we should prohibit both. The argument, as this objection claims, proves too much because we do not want to permit height change, and because the same principles support age change and height change we should jettison those principles.

It is true that people might also be discriminated against due to their height, and the avoidance of discrimination would thus form a prima facie argument for height change. However, while there is a categorical difference between biological age and chronological age, there are no such categories with height. Legal height corresponds with biological height, and obviously, there is no chronological height so the argument presented here does not imply allowing height change. ${ }^{\mathrm{x}}$

Objection 6. If people were allowed to change their legal age then people might misuse this option. For example, someone might change his legal age to older so that he would avoid the duty to work and he would be able to collect retirement benefits instead. Because of the possibility of misusing age change, it should not be an option in the first place.

Reply. I have argued that people should be allowed to change their legal age when they genuinely feel their emotional age does not correspond with their chronological age (and when they fulfil the other conditions mentioned). If someone wants to change his age merely to misuse this option, he would not satisfy this criterion. Age change should not be done lightly. Psychologists and medical doctors should be consulted to find out how serious an age change candidate is and what motivations he has for age change. I doubt that the risk of misuse is so serious that legal age change should not be allowed at all.

\section{Conclusion}

In this paper, I have framed an argument for legal age change and considered objections against it. I have argued that in some cases people should be allowed to change their legal age. Such cases would be when the person genuinely feels his felt age differs significantly from his chronological age and the person's biological age is recognized to be significantly different from his chronological age and age change would prevent, reduce or stop ageism, the discrimination due to age, he would otherwise confront.

I have not offered a full account on when age change should be allowed, but if I am right, there are cases where age change should be allowed. It is up to further studies to determine the exact conditions for legal age change.

\footnotetext{
${ }^{\mathrm{x}}$ An anonymous referee suggested that there could be something like functional height, i.e. one could identify herself taller than she is and could also be capable of doing many of the things taller people are able to do because they jump well or manage to compensate their height another way. So while it would be a slightly different argument (and something a supporter of age change could reasonably contest), height change might be worth considering as well.
} 
1 'Dutchman, 69, brings lawsuit to lower his age 20 years', BBC News, $8^{\text {th }}$ of November 2018. Accessed $10^{\text {th }}$ of November 2018. <https://www.bbc.com/news/world-europe46133262>

${ }^{2}$ Baert S. Norga, J, Thuy Y, Van Hecke M. Getting grey hairs in the labour market. An alternative experiment on age discrimination. J. Econ. Psychol 2016;57:86-101.

${ }^{3}$ Riach PA, Rich J. An Experimental Investigation of Age Discrimination in the English Labor Market. Ann. Econ. Stat 2010;99:169-185.

${ }^{4}$ Albert R, Escot L, Fernández-Cornejo J. A field experiment to study sex and age discrimination in the Madrid labour market. Int. J. Hum. Resour. Man 2011;22:351-375. ${ }^{5}$ Ahmed A, Andersson L, Hammarstedt M. Does age matter for employability? A field experiment on ageism in the Swedish labour market. Appl. Econ. Lett 2012;19:403-406. ${ }^{6}$ Lippert-Rasmussen K. The Badness of Discrimination. Ethical Theory Moral Pract 2006;9:167-185.

${ }^{7}$ Khosravi S. White masks/Muslim names: immigrants and name-changing in Sweden. Race Cl 2012;53:65-80.

${ }^{8}$ Arai M, Thoursie P. Renouncing Personal Names: An Empirical Examination of Surname Change and Earnings. J. Labor Econ 2009;27:127-147.

${ }^{9}$ Han LKM, Aghajani M, Clark SL, et al. Epigenetic Aging in Major Depressive Disorder. Am J Psychiatry 2018;175:774-782.

${ }^{10}$ Paul LA. Transformative Experience. Oxford University Press, 2014.

${ }^{11}$ Paul LA. What You Can't Expect When You're Expecting. Res Philosophica 2015;92:149170.

${ }^{12}$ Corvino J. Homosexuality and the PIB Argument. Ethics 2005;115:501-534.

${ }^{13}$ Tuvel R. In Defense of Transracialism. Hypatia 2017;32:263-278. 